proliferation causes both raised serum lactic dehydrogenase levels and folate deficiency. Cell turnover does not seem sufficiently increased to raise serum lactic dehydrogenase activity in patients with polycythaemia vera, sideroblastic anaemia, chronic lymphatic leukaemia, and in most patients with myelomatosis and chronic haemolytic anaemia, though apparently it may cause some degree of folate deficiency in many of them.

Levitan et al. (1960) found raised serum lactic dehydrogenase activities in four out of five patients with myelosclerosis and normal activities in 64 out of 70 patients with polycythaemia vera. The six patients with polycythaemia and raised serum lactic dehydrogenase levels had developed leukaemia or were in the "spent phase of the disease." However, Paloheimo and Ikkala (1965) found normal serum lactic dehydrogenase levels in both polycythaemia and myelosclerosis. Our findings are consistent with the results of the former workers and show that the estimation of serum lactic dehydrogenase may be useful in diagnosing myelosclerosis at an early stage. This is particularly valuable when myelosclerosis is suspected in a patient with polycythaemia vera. In uncomplicated polycythaemia vera the levels were invariably normal, while in all but one of the patients with myelosclerosis the serum lactic dehydrogenase levels were raised. Folate deficiency is common in myelosclerosis (Chanarin et al., 1958 ; Hogan, Maniatis, and Moloney, 1964 ; Hoffbrand, Kremenchuzky, Chanarin, Szur, and Mollin, 1965), but was excluded as a cause of the high enzyme levels in these cases by correcting this deficiency and re-estimating the levels.

The finding of normal serum lactic dehydrogenase levels in all the patients with sideroblastic anaemia tested was of interest, as in this condition the marrow is often extremely hypercellular and folate deficiency is common (MacGibbon and Mollin, 1965).

\section{Summary}

Serum lactic dehydrogenase was estimated in 17 patients with folate or vitamin- $B_{12}$ deficiency due to gastro-intestinal diseases and in 80 patients suffering from haematological diseases in which increased cell proliferation is a feature.

Serum lactic dehydrogenase levels were extremely high in megaloblastic anaemia whether due to folate or vitamin- $B_{12}$ deficiency. In the non-anaemic patients with gastro-intestinal diseases and obvious megaloblastic change due to either deficiency serum lactic dehydrogenase activities were invariably normal.

Of the patients suffering from disease with increased cell proliferation those with acute leukaemia, acute haemolytic anaemia, thalassaemia, di Guglielmo's disease, and most of those with myelosclerosis and thrombocythaemia had raised serum lactic dehydrogenase levels. The patients with polycythaemia vera, chronic lymphatic leukaemia, chronic acquired haemolytic anaemia, sideroblastic anaemia, and most of those with myeloma had normal serum lactic hydrogenase levels.

There was a definite relation between the serum lactic dehydrogenase activities and serum folate levels of the patients with the haematological diseases with increased cell proliferation ; subnormal serum folate levels occurred in all but one of the patients with raised serum lactic dehydrogenase activities and in a far smaller proportion of those with negative serum lactic dehydrogenase activities. It is concluded that both the raised serum lactic dehydrogenase activities and the subnormal serum folate levels in these diseases are due to increased cell turnover.

Serum lactic dehydrogenase determination appears to be useful in the diagnosis of myelosclerosis, particularly when this is suspected in a patient with polycythaemia.

We wish to thank Dr. R. F. Schilling (U.S.A.) for helpful discussions at the start of this work, and Professor J. V. Dacie, Dr. L. Szur, Dr. C. C. Booth, and the other physicians of the Hammersmith Hospital for permission to publish data on patients under their care. We are grateful to Lieutenant-Colonel W. O'Brien, R.A.M.C., for kindly allowing us to study a patient (Case 7) who was under his care in the Royal Army Hospital, Millbank, London. We also wish to thank Mr. J. Morgan and Miss J. Mercy, who performed the microbiological assays.

\section{REFERENCES}

Anderson, B. B. (1964). F. clin. Path., 17, 14.

Bowman, W. D. (1961). Blood, 18, 662.

Chanarin, I., and Bennett, M. C. (1962). Brit. med. F., 1, 27.

-Mollin, D. L., and Anderson, B. B. (1958). Brit, F. Haemat., 4, 435.

Dacie, J. V., and Lewis, S. M. (1963). Practical Haematology, 3rd ed. Churchill, London.

Smith, M. D., White, J. C., and Mollin, D. L. (1959). Brit. Y. Haemat., 5, 56.

Doniach, I., and Shiner, M. (1960). Brit. 9. Radiol., 33, 238.

Fleming, A. F., and Elliott, B. A. (1964). Brit. med. F., 2, 1108

Gordin, R., and Enari, T.' M. (1959). Acta haemat. (Basel), 21, 360.

Heller, P., Weinstein, H. G., West, M., and Zimmerman, H. J. (1960). 7. Lab. clin. Med., 55, 425.

Hess, B., and Gehm, E. (1955). Klin. Wschr., 33, 91.

Hoffbrand, A. V., Kremenchuzky, S., Chanarin, I., Szur, L., and Mollin, D. L. (1965). To be published.

Hogan, J. A., Maniatis, A., and Moloney, W. C. (1964). Blood, 24, 187.

Hsieh, K. M., and Blumenthal, H. T. (1956). Proc. Soc. exp. Biol. (N.Y.). 91, 626,

$91,626$.

Levitan, R., Wasserman, L. R., and Wróblewski, F. (1960). Cancer (Philad.), 13, 1218.

MacGibon, B. H., and Mollin, D. L. (1965). Brit. F. Haemat., 11, 59.

Mollin, D. L. (1965). Ibid., 11, 41.

Paloheimo, J. A., and Ikkala, E. (1965). Acta med. scand., 177, 115

Szur, L., Lewis, S. M., and Goolden, A. W. G. (1959). Quart. F. Med., 28, 397.

Vessell, E. S., and Bearn, A. G. (1961). 7. clin. Invest., 40, 586.

Waters, A. H., and Mollin, D. L. (1961). Ұ. clin. Path., 14, 335

Wróblewski, F., and LaDue, J. S. (1955). Proc. Soc. exp. Biol. (N.Y.) 90,210 .

Zimmerman,

\title{
Routine Use of Buccal Oxytocin after Amniotomy for Induction of Labour
}

\section{J. M. RITCHIE,* M.R.C.o.g. ; J. M. BRUDENELL,* F.R.C.S., M.R.C.o.G.}

Brit. med. F., 1966, 1, 581-583

Several articles-for example, Maxwell (1964), Blair (1964), and Spence and Chalmers (1964)-have appeared recently showing that oxytocin can be absorbed from the buceal cavity and that this method of administration, properly controlled, can be used easily and safely to induce labour and is readily acceptable to the patient. The success rates claimed are, however, too low to make buccal oxytocin alone a satisfactory method of induc- tion for routine use, and artificial rupture of the membranes remains the most certain method of induction.

Although the success rate for amnictomy is high, there are still cases where labour fails to start promptly or indeed at all.

\footnotetext{
* Department of Obstetrics, King's College and Dulwich Hospitals London.
} 
Such cases are a source of anxiety to the medical and nursing staff and of despondency to the patient, and they block valuable maternity beds. Elstein and Wright (1963) supported the findings of Dillon et al. (1962) that buccal oxytocin provoked ripening of the cervix, and in particular they commented on the increased likelihood of success in unfavourable cases when amniotomy had been preceded by a course of buccal oxytocin. It seemed reasonable to see whether by reversing this order of events, buccal oxytocin after amniotomy, the inductiondelivery interval could be shortened and the number of failed inductions or tardy labours reduced. In many units oxytocics are already used routinely to shorten the induction-delivery interval, the usual scheme being to start an intravenous oxytocin infusion if labour is not established 24 hours after amniotomy. The immediate use of an intravenous infusion to augment the amniotomy is usually objected to on the grounds that, since many patients will be in labour by 24 hours, an intravenous drip is an unnecessary inconvenience to the staff and a source of discomfort-mental and physical-to the patient. These objections would be virtually absent if buccal oxytocin were used, and it was therefore decided to see whether the routine use of this method after amniotomy would result in a worth-while reduction in the induction-delivery interval without complicating management of the case.

\section{Material}

Buccal oxytocin was administered to 79 patients in whom labour was being induced by amniotomy, and the ensuing labours were compared with a control series that had not received buccal oxytocin. To avoid subconscious selection of cases, buccal oxytocin was administered as a routine to all patients undergoing amniotomy ; the only exceptions were cases of disproportion, unconscious or heavily sedated patients, and a small number of patients whose blood-pressure was very high. The distribution of cases is shown in Table $I$.

TABle I.-Distribution of 79 Patients (40 Primiparae, 39 Multiparae) in the Experimental Series

\begin{tabular}{|c|c|c|c|c|c|}
\hline \multirow{2}{*}{ Age } & \multicolumn{5}{|c|}{ Parity } \\
\hline & 0 & 1 & 2 & 3-5 & $6+$ \\
\hline $\begin{array}{l}15-19 \\
20-24 \\
25-29 \\
30-34 \\
35-39 \\
40+\end{array}$ & $\begin{array}{r}8 \\
17 \\
9 \\
7 \\
- \\
-\end{array}$ & $\begin{array}{l}-6 \\
7 \\
2 \\
1 \\
-\end{array}$ & $\begin{array}{l}-2 \\
5 \\
1 \\
-\end{array}$ & $\begin{array}{c}\text { 二 } \\
\frac{1}{3} \\
1 \\
2\end{array}$ & $\begin{array}{l}- \\
3 \\
3 \\
1\end{array}$ \\
\hline
\end{tabular}

Indications for induction: toxaemia, 34; post-maturity, 38 ; others, 7 .

Two control series were used for purposes of comparison, and the cases for these were drawn from those who had had amniotomy during the preceding two years, as listed in the obstetrical tables of this unit. All the amnintomies were performed by low rupture of the membranes, an anaesthetic being used if it seemed indicated. To the best of our beliefs the indications, techniques, and personnel concerned were completely comparable in the experimental period and the period from which the control series were drawn.

In the first control series 250 consecutive cases of amniotomy were taken so that the proportions of primiparae and multiparac matched those of the experimental series. In the second control series an attempt was made to match the controls more accurately with those of the experimental series. Parity $( \pm 25 \%)$, age $( \pm 10 \%)$, maturity, indication for induction, and foetal weight ( $\pm \frac{1}{2} \mathrm{lb}$. ; $227 \mathrm{~g}$.) were all taken into consideration, and the first case in the Tables to meet these criteria was chosen as the control. No case was used a second time in the same control series. As with the experimental series, cases of disproportion and of severe toxaemia, and unconscious patients, were excluded.

\section{Method}

The basic principles and precautions for the use of buccal oxytocin are now adequately documented, and only those aspects relevant to the present matter are discussed. Any person using buccal oxytocin must constantly keep in mind the dangers of uterine tetany and rupture, which can easily occur if due care is not exercised (Masheter, 1965). After amniotomy buccal oxytocin was administered according to the dosage schedule shown in Table II. Once labour was established no

TABLE II.-Dosage Schedule for Buccal Oxytocin

\begin{tabular}{|c|c|c|c|c|c|c|c|c|c|c|c|c|}
\hline Time (hours) & $\begin{array}{l}\dot{x} \\
\dot{\alpha} \\
\dot{4}\end{array}$ & $+\frac{1}{2}$ & +1 & $+1 \frac{1}{2}$ & +2 & $+2 \frac{1}{2}$ & +3 & $+3 \frac{1}{2}$ & +4 & $+4 \frac{1}{2}$ & +5 & $+5 \frac{1}{2}$ \\
\hline $\begin{array}{l}\text { Dose (tablets) } \\
1 \text { tab. }=200 \\
\text { units } \\
\text { Amended dose }\end{array}$ & Nil & Nil & $\frac{1}{2}$ & $\frac{1}{2}$ & 1 & $1 \frac{1}{2}$ & 2 & $2 \frac{1}{2}$ & 3 & 3 & 3 & 3 \\
\hline (tablets) $\ldots$ & Nil & Nil & $\frac{1}{2}$ & $\frac{\pi}{2}$ & 1 & 1 & 2 & 2 & 3 & 3 & 3 & 3 \\
\hline
\end{tabular}

further tablets were administered, and in any case no more tablets were given after completion of the course shown. If labour did not begin after administration of the tablets then any subsequent management was exactly that for cases before the present experiment.

The first 20 cases were supervised by one of us (J.M.R.) at half-hourly intervals. For the remaining cases the technique was simplified slightly to find whether it could satisfactorily be left in the hands of the nursing staff with minimal medical supervision. The dosage scale was amended (Table II) to exclude half-tablets except for the initial test doses, and a chart was printed to show on a single page the dosage schedule, simple rules for amending the dosage to meet the individual's response to the induction, and recordings of blood-pressure, pulse, and foetal heart rate at half-hourly intervals (see Chart).

Buccal Oxytocin Chart

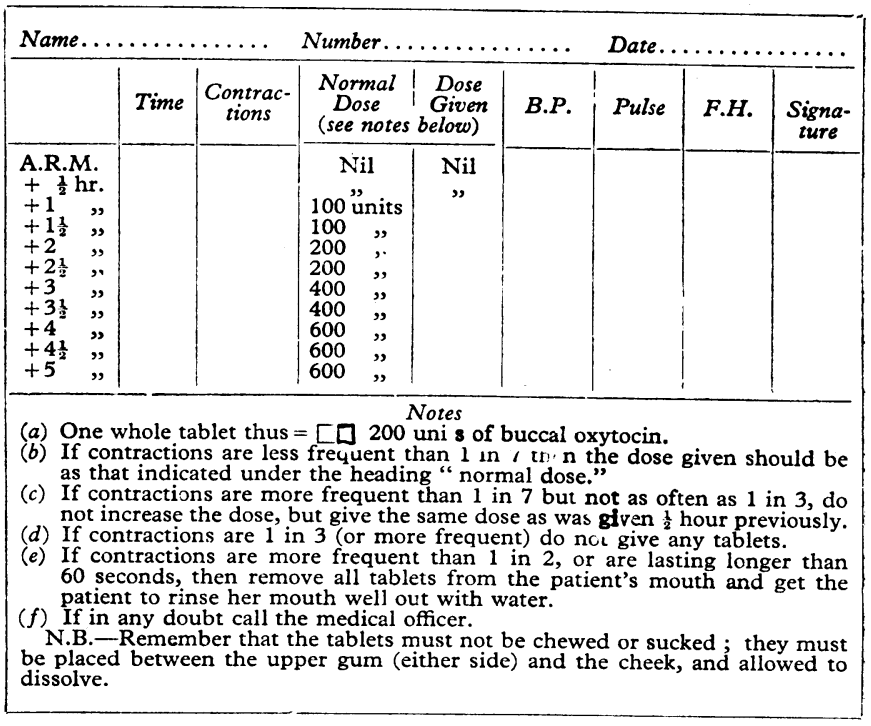

This simplified technique was found to be very satisfactory. The average number of tablets required to establish labour was 8 (1,600 units of oxytocin).

\section{Results}

Induction-Delivery Interval.-The experimental series was compared with both control series with regard to the average induction-delivery interval and the numbers of patients not delivered 24 hours after amniotomy. The results (Table III) show a reduction of over $30 \%$ in the induction-delivery interval 
and nearly $60 \%$ in the number of patients not delivered in 24 hours.

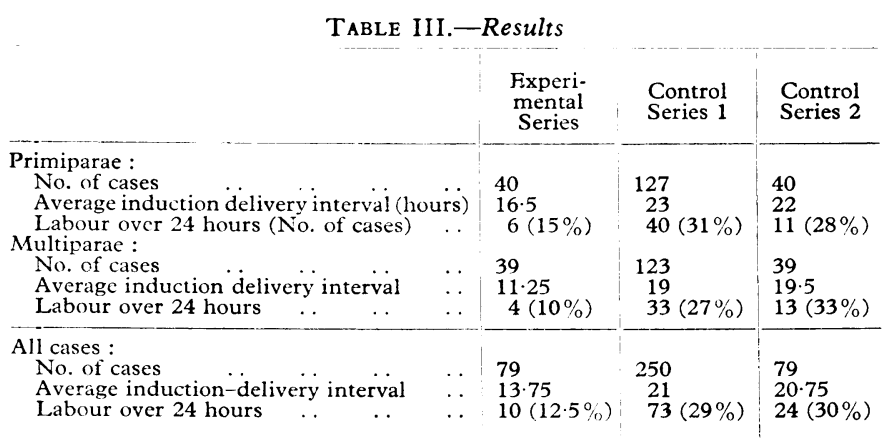

Forceps Deliveries.-Six patients $(7.5 \%)$ were delivered by forceps compared with $7 \%$ for all those delivered in the preceding year. Four of these deliveries were performed for delay in the second stage (two transverse arrest, one persistent occipito-posterior, one hypotonic inertia) and two for foetal distress in the second stage.

Caesarean Section.-Three cases required section-one for failure to progress in labour and two for foetal distress before full dilatation.

Post-partum Haemorrhage.-Four patients (5\%) had a blood loss exceeding $500 \mathrm{ml}$. This compares with $5.1 \%$ for the preceding year.

Uterine Tetany.-In no case did true tetany occur. In two cases strong uterine contractions were occurring every two minutes. The first of these cases was a primiparous patient who was established in labour and had had no tablets for an hour. A small quantity of tablet was left in her buccal space, and this was removed. Within 10 minutes the contractions had settled to one every three minutes; the foetal heart rate remained steady between 136 and 144 beats a minute throughout. The second patient was also primiparous and was at the end of her course of tablets. The contractions had built up from "vague" to one every two minutes over the course of an hour and a half. She also responded rapidly to removal of the tablets, and again showed no signs of foetal distress.

Foetal Distress.-There were four cases in which action was taken on a diagnosis of foetal distress.

1. An elderly primiparous patient underwent induction for postmaturity. Six hours after her last tablet of oxytocin, at almost full dilatation, the foetal heart rate, which had been normal, dropped to 90 beats a minute. After a difficult forceps case a markedly asphyxiated baby was delivered which responded slowly to resuscitation.

2. In a primiparous patient induced for post-maturity the foetal heart rate dropped to 100 a minute, irregular, at $7-\mathrm{cm}$. dilatation, some three hours after her last tablet of oxytocin. The contractions at the time occurred every 10 minutes and the baby required minimal resuscitation after caesarean section.

3. A patient having her second baby was induced at 38 weeks for moderately severe hypertension; her last child had been born 12 years previously. At $6-\mathrm{cm}$. dilatation the foetal heart became very irregular, and, although she was having oxytocin tablets at the time, the contractions were occurring only every 10 minutes and were weak. The irregularity persisted despite stopping the tablets, and caesarean section was performed. The baby cried at once.

4. A primiparous patient had induction for post-maturity and developed meconium staining of the liquor in the second stage seven hours after the last oxytocin tablet. This appeared to be associated with a posterior position arrested on the pelvic floor. The baby was delivered with forceps and cried at once; the foetal heart rate was normal throughout.
Perinatal Mortality.-One infant in the series died seven hours after birth. The mother (a primipara) underwent induction for post-maturity and responded well, receiving a total of four tablets (800 units). Twelve hours after the last tablet she reached full dilatation; the second stage was rapid, lasting 15 minutes. The foetal heart rate had been normal throughout, but after birth the baby required intubation and it took 10 minutes to establish respiration. Several apnoeic attacks occurred in the ensuing hours, and during one of them the baby died. Post-mortem examination revealed asphyxial changes only.

\section{Comment}

The results indicate that a useful reduction in the inductiondelivery interval can be obtained by the administration of buccal oxytocin after amniotomy, and this improvement occurs without significantly complicating management of the case. Patients readily accepted the treatment and benefited both psychologically and medically.

Perusal of the results, however, suggests that the technique could be simplified even further without any impairment of the overall results. When drawing up the first control series -250 routine inductions-it was noticed that $25 \%$ of the patients were in labour within three hours of the amniotomy, and all of these were delivered within 24 hours. It would seem that the technique could be modified so that the administration of tablets began three hours after amniotomy if the patient was not in labour, and not one hour as in this experiment. A further series along these lines is being carried out.

Further, the impression was gained that perhaps similarly good results could be obtained with smaller doses of oxytocin, thus emulating the physiological drip of Theobald et al. (1948) rather than a pharmacological one. Experiments along these lines are also being carried out.

\section{Summary}

Buccal oxytocin was administered to a series of 79 patients who were being induced by amniotomy. A simple schedule of dosage was drawn up which allowed of minimal supervision by the medical staff.

Compared with the control series, the induction-delivery interval was reduced by about a third, and the number of patients not delivered in 24 hours by over a half.

No untoward reactions were noted that could be attributed to the buccal oxytocin.

Further investigations are outlined which aim at reducing the dose of oxytocin required and the number of patients to whom it need be given after amniotomy.

We are grateful to Parke Davis \& Co., who in the earlier stages of this work supplied us with buccal oxytocin before it was generally available.

\section{REFERENCES}

Blair, R. G. (1964). Lancet, 1, 637.

Dillon, T. F., Douglas, R. G., and du Vigneaud, V. (1962). Obstet. and Gynec., $20,434$.

Elstein, M., and Wright, H. P. (1963). F. Obstet. Gynaec. Brit. Cwlih, 70, 1005 .

Masheter, H. C. (1965). In Advances in Oxytocin Research, edited by J. H. M. Pinkerton, p. 113. Pergamon Press, London J. H. M. Pinkerton, p. 113. Pergamon Press, London.
Maxwell, A. W. (1964). f. Obstet. Gynaec. Brit. Cwlth, 71, 37. Maxwell, A. W. (1964). F. Obstet. Gynaec. Brit. Cwlth, 71, 37.
Spence, D. N., and Chalmers, J. A. (1964). Lancet, 1, 633.

Spence, D. N., and Chalmers, J. A. (1964). Lancet, 1, 633 .
Theobald, G. W., Graham, A., Campbell, J., Grange, P. D., and Driscoll

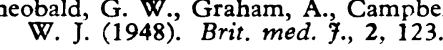

